J. Dairy Sci. 95:3549-3558

http://dx.doi.org/10.3168/jds.2011-5124

(C) American Dairy Science Association ${ }^{\circledR}, 2012$.

\title{
Probiotic cheese attenuates exercise-induced immune suppression in Wistar rats
}

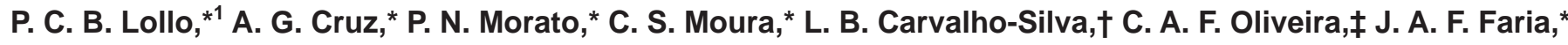 \\ and J. Amaya-Farfan* \\ *Universidade Estadual de Campinas (UNICAMP), Faculdade de Engenharia de Alimentos (FEA), Cidade Universitária Zeferino Vaz, 13083-862, \\ Campinas, São Paulo, Brazil \\ †Universidade Federal de Alfenas (UNIFENAS), Departamento de Nutrição, 37130-000, Alfenas, Minas Gerais, Brazil \\ łUniversidade de São Paulo (USP), Faculdade de Zootecnia e Engenharia de Alimentos Campus da USP (FZEA), Pirassununga, \\ CEP 13635-900, São Paulo, Brazil
}

\section{ABSTRACT}

Intense physical activity results in a substantial volume of stress and hence a significant probability of immunosuppression in athletes, with milk proteins being, perhaps, the most recommended protein supplements. Consumption of a probiotic cheese can attenuate immune suppression induced by exhausting exercise in rats. A popular Brazilian fresh cheese (Minas Frescal cheese) containing Lactobacillus acidophilus LA14 and Bifidobacterium longum BL05 was fed for 2 wk to adult Wistar rats, which then were brought to exhaustion on the treadmill. Two hours after exhaustion, the rats were killed and material was collected for the determination of serum uric acid, total and high-density lipoprotein cholesterol fraction, total protein, triacylglycerols, aspartate aminotransferase, alanine aminotransferase, creatine kinase, and blood cell (monocyte, lymphocyte, neutrophil, and leukocyte) counts. Exercise was efficient in reducing lymphocyte counts, irrespective of the type of ingested cheese, but the decrease in the group fed the probiotic cheese was $22 \%$ compared with $48 \%$ in the animals fed regular cheese. Monocyte counts were unaltered in the rats fed probiotic cheese compared with a significant decrease in the rats fed the regular cheese. Most importantly, ingestion of the probiotic cheese resulted in a $>100 \%$ increase in serum high-density lipoprotein cholesterol and a $50 \%$ decrease in triacylglycerols. We conclude that probiotic Minas Frescal cheese may be a viable alternative to enhance the immune system and could be used to prevent infections, particularly those related to the physical overexertion of athletes.

Key words: probiotic cheese, exercise, immune system, probiotic bacteria

Received November 6, 2011.

Accepted February 18, 2012.

${ }^{1}$ Corresponding author: pablo@fea.unicamp.br

\section{INTRODUCTION}

Dairy foods are the main types of foods matrices supplemented with probiotic bacteria, and they have a positive reputation among consumers (Granato et al., 2010). Among dairy products, cheese can be an adequate matrix for supplementation with probiotic bacteria because it presents intrinsic advantages such as high water activity and buffering capacities, leading to better protection of these bacteria during passage through the gastrointestinal tract (Cruz et al., 2009; Karimi et al., 2011).

Regular consumption of probiotic foods can provide health benefits, including modification of the immune system (Pyne and Gleeson, 1998; Mackinnon, 2000; Gill and Cross, 2002; Saxelin et al., 2003; Borchers et al., 2009; Minocha, 2009). The ingestion of probiotics can increase resistance to infection in the upper respiratory tract of athlete subjects (de Vrese et al., 2006), common infection illnesses, and gastrointestinal illnesses (West et al., 2011). Stressing situations such as those derived from intense physical exercise can increase the incidence of gastrointestinal disease episodes, particularly of diarrhea during heavy training (Pyne and Gleeson, 1998; Mackinnon, 2000).

Because the consumption of dietary and supplemental milk proteins is common among athletes, it may be possible to improve the athlete's regular diet by adding a functional food such as probiotic cheese. During intense training periods, for instance, athletes participating in rowing, cycling, swimming, and triathlon are likely to develop increased susceptibility to infections of the upper respiratory tract (Pyne and Gleeson, 1998; Gleeson, 2000; Mackinnon, 2000), and it is hypothesized that some adverse health events among athletes could be averted by improving routinely consumed diet components such as cheese. Pyne et al. (2001) observed that both athletes and coaches are interested in minimizing gastrointestinal disorders, particularly diarrhea, during 
travel for international competitions, which adversely affect adaptation periods and physical performance.

Therefore, probiotics could be used to indirectly maximize athletic performance by preventing the immunosuppression caused by prolonged sessions of intense physical exercise and thus reduce the athlete's susceptibility to disease (Berg et al., 1999; Nichols, 2007). Intervention evidence has shown the effectiveness of probiotics in reducing the incidence of acute infections, diarrheas, and their associated symptoms (Pregliasco et al., 2008; Guarino et al., 2009). Population studies also support the effectiveness of probiotics in increasing the body's resistance to infections of the upper respiratory tract (de Vrese and Schrezenmeir, 2008).

The ingestion of cheese supplemented with probiotic bacteria has been associated with a variety of benefits to human health, such as improvements in the immune system (Ibrahim et al., 2010), improvements in oral and intestinal health in the elderly (Hatakka et al., 2007; Lahtinen et al., 2012), and reinforcement of intestinal immunity (Medici et al., 2004) and gastrointestinal health (Modzelewska-Kapituła et al., 2010). However, many of the alterations induced in the immune system by intense exercise are similar to those associated with several forms of stress, such as sleep deprivation, aging, and psychological stress (Hamer et al., 2004). Because intense exercise is related to a transitory depression of the immune function (Gleeson, 2007), and because the consumption of some probiotic foods (West et al., 2009) can be specifically targeted to athletes, this study aimed to evaluate alterations in key parameters of the immune system of Wistar rats that were submitted to acute, intense physical exercise after receiving a diet with probiotic cheese for $14 \mathrm{~d}$.

\section{MATERIALS AND METHODS}

Male (21-d-old, specific-pathogen-free) Wistar rats, bred at the Multidisciplinary Center for Biological Research (University of Campinas, SP, Brazil), were housed $\left(\sim 22^{\circ} \mathrm{C}, 55 \%\right.$ relative humidity, inverted 12 -h light /12-h dark cycles) in individual growth cages, with free access to commercial chow (Labina, Purina, Brazil) and water at all times, until they reached a BW of $111.8 \pm 7.1 \mathrm{~g}$. The research methodology was approved by the Ethics Committee on Animal Experimentation (CEEA-UNICAMP, protocol 2345-1). The animals were randomly assigned to 1 of 4 groups, depending on whether the diet was probiotic cheese or conventional cheese, and whether rats were exercised or remained sedentary. In each day, $20 \mathrm{~g}$ of cheese was placed in each cage and that amount was completely ingested (Figure 1). As we were focused in the compari-

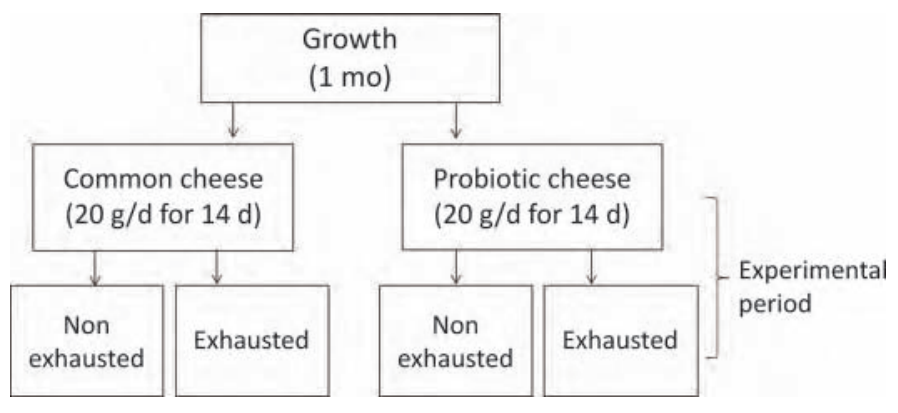

Figure 1. Distribution of groups and experimental design.

son between probiotic versus conventional cheese, the control group received conventional cheese. Similar experimental designs have been pursued in other studies with probiotic and conventional dairy foods (Ejtahed et al., 2011; Savard et al., 2011; Lahtinen et al., 2012).

\section{Probiotic Strain}

The probiotic strains used in our study were Lactobacillus acidophilus LA 14 and Bifidobacterium longum BL 05 (Danisco, São Paulo, Brazil). These probiotic bacteria have been used in several commercial dairy products available on the Brazilian market (Saad et al., 2011), as well as in previous studies covering dairy foods (De Almeida et al., 2008; Cruz et al., 2010, 2011, 2012a,b,c; Espírito Santo et al., 2010with prominent beneficial effects for human and animal health (Paineau et al., 2008; Ogué-Bon et al., 2011) as well as the production of bacteriocin (Todorov et al., 2011).

To choose the strains used in this work, we considered their previous use in Brazilian dairy products as well as the possibility of discovering new beneficial effects associated with their ingestion. Today, because of the various health benefits attributed to physical exercise and a nationwide campaign by the media, about $30 \%$ of the Brazilian population has adopted an active lifestyle (Agencia Estado, 2009). In this context, the possibility of exploring the effect of adding probiotic bacteria to the widely consumed cheese Minas Frescal becomes attractive, not only because of the scientific interest, but also because of its relevance to the general state of health of the population. To our knowledge, this is the first study to consider the effect of ingesting a protein-rich prebiotic cheese on the health of the physical fitness-oriented consumer.

\section{Food Matrix}

Minas fresh cheese (Minas Frescal) is one of the most highly consumed dairy products in Brazil because of its acceptability on the national market (Pflanzer Junior 
et al., 2009). It is a fresh, soft, white cheese, slightly salted and with a slight lactic acid taste (Souza et al., 2008). In fact, previous researchers have reported the development of a low-sodium Minas cheese (Gomes et al., 2011b) as well as the supplementation of Minas cheese with probiotic bacteria (Buriti et al., 2005a,b; Souza and Saad, 2009; Fritzen-Freire et al., 2010a,b).

\section{Cheese Processing}

Cheese processing was performed in accordance with methods published elsewhere (Gomes et al., 2011a) with some modifications. The lactic (Lactococcus lactis Choozit, Danisco, São Paulo, Brazil) and probiotic cultures were added to obtain concentrations of approximately 6 and $7 \log \mathrm{cfu} / \mathrm{g}$ in the cheese, respectively. Both cultures were freeze-dried commercial cultures for direct vat inoculation, and adequate distribution throughout the milk was ensured by manual homogenization for 2 min. Powdered rennet (Halamix power, Chr. Hansen, São Paulo, Brazil) was added at a concentration of $3 \mathrm{~g} / \mathrm{L}$ of milk, and the mixture was homogenized again for 2 min. The resulting cheesemilk was kept at $37^{\circ} \mathrm{C}$ for $40 \mathrm{~min}$ to coagulate. The curd was then cut, the whey run off, and the remaining curd placed in 250 -g plastic molds. The cheeses were submitted to dry salting $(0.8 \%$ wt/vol NaCl, Labsynth, São Paulo, Brazil), vacuum-packaged, and stored in a cold room at 5 to $7^{\circ} \mathrm{C}$ for $14 \mathrm{~d}$. Two types of cheese were manufactured: the conventional (common) cheese, containing the starter culture Lactococcus lactis Li 23 (Danisco), without any probiotic bacteria, and probiotic cheese containing the starter and probiotic cultures. The viable counts of lactic and probiotic bacteria measured at 1 and $14 \mathrm{~d}$ of refrigerated storage were 7.4 to $7.7,6.7$ to 7.2 , and 7.3 to $7.8 \log \mathrm{cfu} / \mathrm{g}$ of Lc. lactis, B. longum, and $L b$. acidophilus, respectively. This emphasizes that cheese is an adequate food matrix for probiotic bacteria supplementation (Albenzio et al., 2010; Madureira et al., 2011 a,b,c; Minervini et al., 2012).

\section{Exhaustion Protocol}

The rats were acquainted to the treadmill by running for $10 \mathrm{~min}$ at $10 \mathrm{~m} / \mathrm{min}$ on the day before being brought to exhaustion. The exhaustion test was applied following the time-speed schedule shown in Table 1.

\section{Biochemical Parameters}

Two hours after the exhaustion session, blood samples were collected in BD Vacutainers (Becton Dickinson, Franklin Lakes, NJ), kept at $4^{\circ} \mathrm{C}$, and centrifuged at $3,000 \times g\left(4^{\circ} \mathrm{C}, 12 \mathrm{~min}\right)$ to obtain serum for the assess- ment of serum, uric acid, total cholesterol and highdensity lipoprotein (HDL) cholesterol, total protein, triacylglycerols, aspartate aminotransferase (AST), alanine aminotransferase (ALT), and creatine kinase (CK). Glucose and cholesterol standard enzymatic spectrophotometric determinations were performed using Laborlab kits (São Paulo, Brazil) in a Biotech microplate reader EPOCH (BioTek, Winooski, VT).

\section{AA Composition of the Cheese}

Amino acids were extracted with methanol and derivatized with phenylisothiocyanate (White et al., 1986), and the phenylthiohydantoin derivatives underwent chromatography using a Luna C-18, $100 \AA \AA, 5 \mu \mathrm{m}, 250$ $\times 4.6 \mathrm{~mm}$ column (00G-4252-EQ, Phenomenex, Torrance, $\mathrm{CA}$ ), at $50^{\circ} \mathrm{C}$. Quantification was by comparison with a standard mixture with DL-2-aminobutyric acid as an internal standard (Sigma-Aldrich Corp., St Louis, $\mathrm{MO})$. The free AA were determined by extracting 1.25$\mathrm{g}$ flour samples in $80 \%$ ethanol and $0.1 \mathrm{M} \mathrm{HCl}$, with 500 $\mu \mathrm{L}$ of $\alpha$-aminobutyric acid added as internal standard, in a $5-\mathrm{mL}$ volumetric flask. The mixture was sonicated for $10 \mathrm{~min}$ and further homogenized for $1 \mathrm{~h}$, followed by centrifugation at $8,500 \times g$ for $15 \mathrm{~min}$. The supernatant was filtered through a $0.22-\mu \mathrm{m}$ membrane and a $40-\mu \mathrm{L}$ aliquot derivatized as described above for injection of $20 \mu \mathrm{L}$ into the liquid chromatograph.

\section{Proximal Composition of Cheeses and Diets}

Moisture, total ash, protein, and lipids were determined according to AOAC (2002) methods. The total carbohydrate content was inferred by difference. The experimental diets were isonitrogenous (approximately $16 \%$ protein, dry basis), isolipidic, and isocaloric (approximately $360 \mathrm{kcal} / 100 \mathrm{~g}$ ). Proximal composition and AA contents of cheese and diets are in Table 2.

\section{Blood Cell Counts}

Blood samples in the K3 EDTA Vacutainer (4 mL) were used for hematological analysis using an auto-

Table 1. Schedule of the protocol to exhaustion ${ }^{1}$

\begin{tabular}{lc}
\hline Time $(\mathrm{min})$ & Speed $(\mathrm{m} / \mathrm{min})$ \\
\hline 1 to 90 & 15 \\
91 to 100 & 20 \\
150 to exhaustion & 22 \\
\hline
\end{tabular}

${ }^{1}$ Half of the 51-d-old rats $(n=16)$ were fed the conventional cheese, whereas the other half $(\mathrm{n}=16)$ were fed the probiotic cheese for $2 \mathrm{wk}$. On d 15, half of each group $(n=8)$ were taken to the treadmill and brought to exhaustion following the schedule shown. 
Table 2. Proximal composition and AA of the diet and cheeses (common and probiotic)

\begin{tabular}{lrrr}
\hline Item & Diet & $\begin{array}{c}\text { Common } \\
\text { cheese }\end{array}$ & $\begin{array}{c}\text { Probiotic } \\
\text { cheese }\end{array}$ \\
\hline Macronutrient (\% of total) & & & \\
Lipids & 5.1 & 18.2 & 20.1 \\
Ash & 8.3 & 2.7 & 3.0 \\
Moisture & 9.0 & 55.9 & 54.7 \\
Protein & 21.8 & 16.7 & 15.9 \\
Carbohydrate & 55.8 & 6.5 & 6.3 \\
Amino acid (g/100 g) & & & \\
Asp & 2.00 & 1.23 & 1.48 \\
Glu & 4.03 & 4.68 & 3.94 \\
Ser & 1.08 & 1.02 & 1.25 \\
Gln & 0.97 & 0.34 & 0.43 \\
His & 0.54 & 0.54 & 0.66 \\
Arg & 1.61 & 0.81 & 0.94 \\
Thr & 0.78 & 0.67 & 0.85 \\
Ala & 1.04 & 0.53 & 0.64 \\
Pro & 1.28 & 1.92 & 2.32 \\
Tyr & 0.78 & 1.07 & 1.28 \\
Met & 0.45 & 1.11 & 1.33 \\
Cys & 0.28 & 0.77 & 0.87 \\
Val & 1.00 & 0.09 & 0.09 \\
Ile & 0.89 & 0.92 & 1.06 \\
Leu & 1.76 & 1.78 & 2.08 \\
Phe & 1.07 & 1.03 & 1.15 \\
Lys & 1.15 & 1.63 & 1.74 \\
\hline
\end{tabular}

mated cell counter (Ac.T5diff hematology analyzer, Beckman Coulter, High Wycombe, UK). The intraassay coefficient of variation for all measured variables was $<3.0 \%$.

\section{Statistical Analysis}

The results were submitted to statistical analysis using SPSS software (version 17.0, SPSS Inc., Chicago, IL). The data were tested for normality (KolmogorovSmirnov test) and homogeneity using the tools available therein. For parametric data, the monovariate ANOVA was used and means were compared (Duncan test), adopting the value of $P \leq 0.05$ as a criterion for statistical significance.

The Ethics Committee on Animal Experimentation (CEEA-UNICAMP, protocol 2345-1), which follows international recommendations, authorized the use of the current number of animals to protect animal life. The CEEA-UNICAMP indicated that reliable scientific results could be reached (considering other statistical analyses different from power analysis) with this number of animals, and that this study adhered to American College of Sports Medicine animal care standards.

\section{RESULTS AND DISCUSSION}

Based on the reported ability that probiotics possess to improve the immunocompetence and minimize the immunosuppression that follow intense, prolonged exercise, the objective of this study was to assess the effect that the consumption of a probiotic cheese could produce on the immune system of sedentary Wistar rats submitted to a bout of intense, acute physical exercise. It has been proposed that physical exercise can work as a suitable model to quantify stress (Hoffman-Goetz and Pedersen, 1994). Therefore, this study showed (Tables 2 and 3 ) that the exercise protocol used was sufficient and adequate to significantly suppress immune parameters and that consumption of the probiotic cheese was capable of attenuating the exercise-induced depression (Figure 2). The levels of monocytes, which decreased in the exercised animals consuming the conventional cheese, were normal in both the sedentary and exercised rats that consumed the probiotic cheese (Figure $2 \mathrm{~A})$. On the other hand, the undesirable segmented or immature neutrophils were low in both the sedentary and the exercised animals that consumed the probiotic cheese. An analogous observation can be drawn from Figures $2 \mathrm{C}$ and $2 \mathrm{D}$, where the levels of the desirable lymphocytes and leucocytes did not decrease with exercise only in the animals that were fed the probiotic diet.

It is known that training alone is capable of attenuating the immunosuppression caused by acute exercise (Senchina, 2009), so that a single session of intense exercise may be sufficient to exacerbate the effects of exercise on the immune system. In general terms, depression of the immune function is directly proportional to the intensity and duration of the exercise (Gleeson, 2007), and this is consistent with the alterations observed in Figure 2.

Cheeses can be an efficient vehicle for the delivery of probiotic species because, in addition to possessing relatively high contents of desirable lipids, their proteins can function as buffers against the acid stomach, thus favoring the survival of the probiotic species in the gastrointestinal tract (Ross et al., 2002; Bergamini et al., 2005).

The immune system functions to recognize, attack, and destroy elements foreign to the organism. The system can be divided into innate (or nonspecific) and acquired (or specific), and both work synergistically. The innate immune system is activated as soon as an infectious agent tries to invade the organism. After passing the first physical and chemical barriers (skin, mucosa, stomach $\mathrm{pH}$, action of body secretions, lyso enzymes and proteins), the phagocytic cells (neutrophils, monocytes, macrophages, and natural cytotoxic killer cells) are recruited to combat the invading agent. If the innate immune system fails to completely eliminate the threat, the acquired immune system is recruited to activate lymphocytes with antigen receptors produced by macrophages and monocytes, and to mediate a 
humoral response through the production of specific antibodies. Thus, a characteristic of the immune system is the involvement of different types of cells, which act in a coordinated manner through the production of cytokines, which in turn function as signalers of an orchestrated immune response among the different cells against the infectious agent (Keil et al., 2001). Therefore, the evaluation of the correct functioning of the immune system requires the quantification of a large number of variables.

Observing the parameters of the immune system that were evaluated in the current study (Figure 2A), a significant $(P<0.001)$ decrease in the monocyte counts was seen in rats fed the common cheese and submitted to exhaustive exercise, as was also observed in the study of Rowbottom and Green (2000). However, for the animals that were fed the probiotic cheese, the changes in monocyte counts after exhaustion did not differ statistically from those of the nonexercised cohorts, regardless of the cheese type. Typically, the concentration of neutrophils increases during and after exercise, whereas the concentration of lymphocytes increases but then falls below initial values after long-lasting exercise (McCarthy and Dale, 1988). We observed an increase $(P$ $<0.001)$ in the concentration of neutrophils for rats fed both cheese types (Figure 2B), but the basal and postexhaustion levels were significantly lower for rats fed probiotic cheese compared with those fed common cheese. However, probiotic bacteria have been implicated in an improvement in the lipid profile (Fabian and Elmadfa, 2006; Asemi et al., 2011; Ejtahed et al., 2011), which suggests a relationship between blood lipids and immune response (Inouye et al., 2010; Im et al., 2011). Therefore, it is possible that part of the immune changes that were seen in this study were actually related to intrinsic changes in the levels of lipids caused by the ingestion of probiotics. Further studies are necessary to better elucidate this.

Exercise was also efficient in reducing the concentrations of lymphocytes, regardless of the cheese ingested, but the decrease observed in rats fed probiotic cheese was significantly smaller, $22 \%$, compared with the $48 \%$ decrease in rats fed the common cheese (Figure 2C; $P$ $<0.001)$. The neutrophil:lymphocyte ratio has been proposed as a fast and simple indicator of stress intensity and inflammatory state (Zahorec, 2001), with intense and acute exercise being able to induce muscle microwounds and inflammatory response in the organism (Woods et al., 2009).

The decrease in neutrophils and elevation of lymphocytes is indicative of inflammatory states and the appearance of infections. In rats fed probiotic cheese, the neutrophil:lymphocyte ratio was 2.2 -fold higher $(P$ $<0.001)$ after exhaustive exercise, whereas in rats fed 

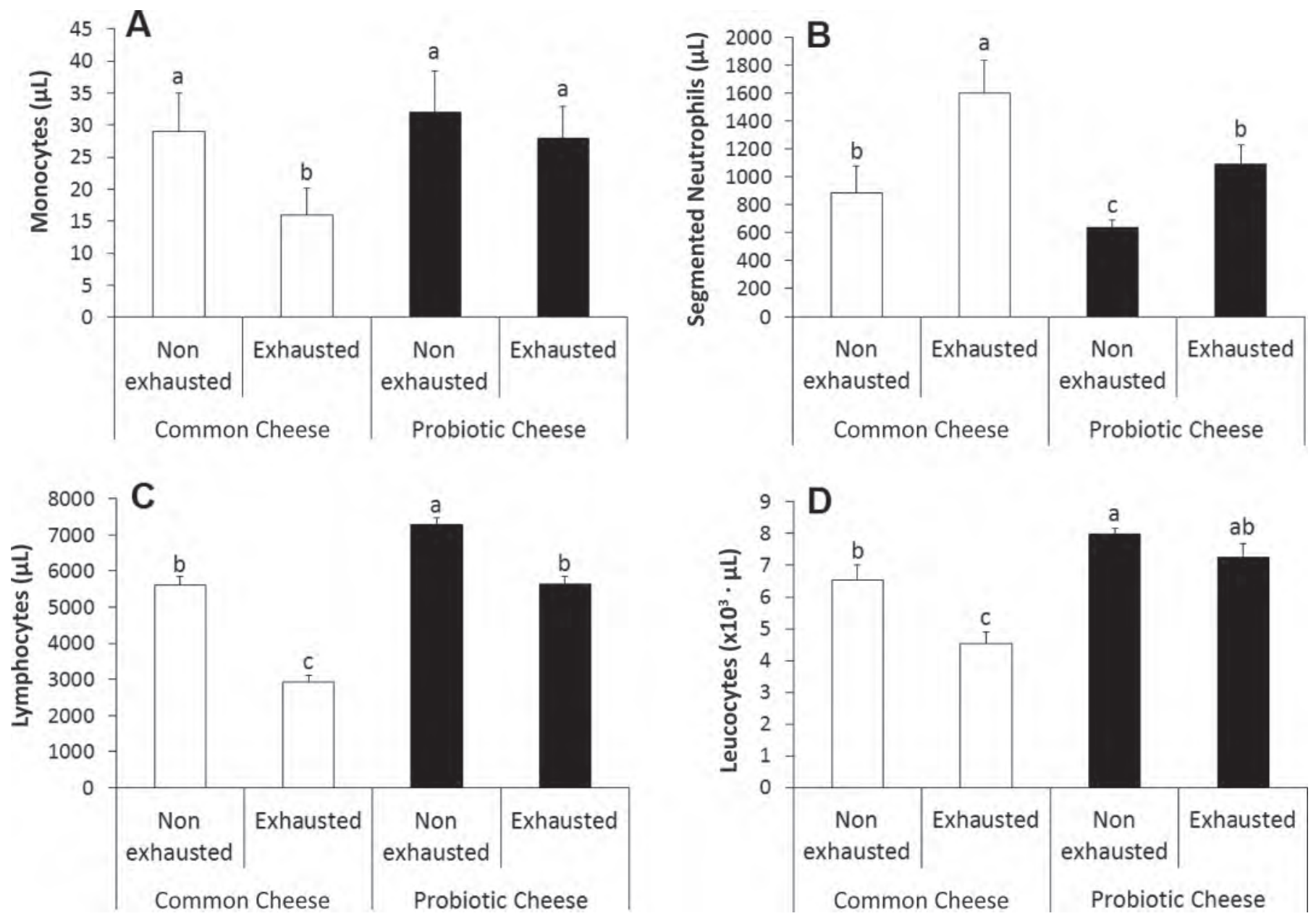

Figure 2. Immune system parameters in Wistar rats fed common ( $\square$ ) or probiotic

cheese.

common cheese, this ratio was elevated $(P<0.001) 3.5-$ fold, indicating that the inflammatory state typically occurring after lasting and exhaustive exercise may be lowered due to consumption of probiotics. One explanation for the changes in postexercise immune system would be that the muscle microwounds generated by intense exercise would increase the production of cytokines, eliciting an influx of lymphocytes, neutrophils, monocytes, and other types of cells to heal the damaged tissue (Pedersen and Hoffman-Goetz, 2000).

The causes and functions of the alterations on the immune system that follow exercise are not completely understood, but at least 2 links of interaction between exercise and the immune system have been identified: (1) hormonal responses, and (2) production of free radicals. Exercise modulates many hormones such as cortisol, glucagon, insulin, epinephrine, and norepinephrine (Brenner et al., 1998), and these hormones are able to modulate the immune system (Pedersen and Hoffman-Goetz, 2000). Among the most influen- tial hormones in the interaction between exercise and immune response are the stress hormones epinephrine and cortisol (Steensberg et al., 2000; Steensberg, 2003). The function and number of leukocytes are affected by catecholamines (Steel et al., 1987), which are increased by exercise (Blannin et al., 1996), in agreement with data from this work (Figure 2D).

Exercise is also responsible for the production of free radicals. Just one session of exhaustive exercise is able to significantly increase the production of free radicals (Bloomer, 2008), and cells of the immune system may be vulnerable to oxidative stress (Gill et al., 2010). The ingestion of probiotics is able to increase the levels of plasma antioxidants and neutralize the effects of oxygen reactive species. Furthermore, the stimulation of the immune system decreases the inflammatory state and prevents oxidative stress induced by cytokines (Martarelli et al., 2011). Because of the possible antioxidative and antiinflammatory properties of probiotics, benefits would be conferred to the immune system 
Table 4. Mean macronutrient intake ${ }^{1}$

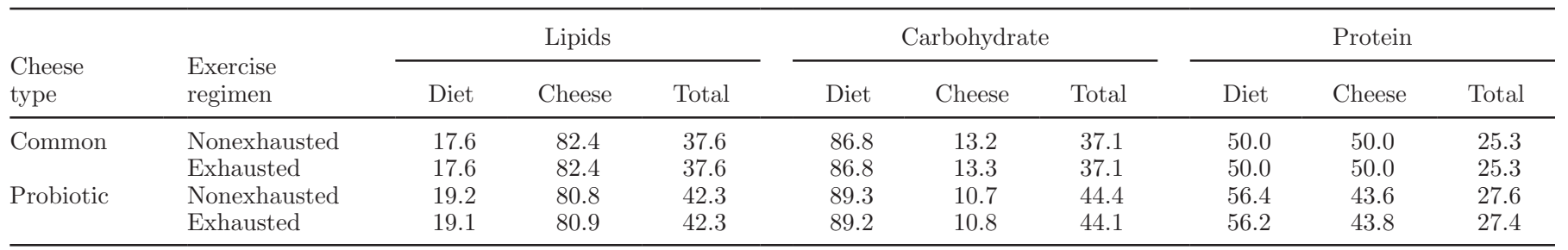

${ }^{1}$ Total intake $=$ percentage of total energy ingested. Groups did not differ significantly $(P>0.05)$.

of sedentary hosts submitted to exhaustive exercise, consequently neutralizing the production of reactive species of oxygen (Martarelli et al., 2011).

The proximal and AA composition (Table 2) of the 2 diets and the consumption of macronutrients (Table 4) did not differ significantly $(P>0.05)$, as the control and experimental groups received the same amount of nutrients present in the cheese (Table 4), except for the probiotics.

It is worth mentioning that glutamine, an amino acid known to stimulate the immune system (Abcouwer, 2000), showed similar concentrations in both groups, and hence no glutamine-dependent immune modulation occurred. We also observed that the probiotic cheese caused a $100 \%$ increase $(P<0.001)$ in HDL cholesterol and exercise decreased TAG by $50 \%(P=$ 0.008; Table 5), which is in agreement with findings of other researchers (Ataie-Jafari et al., 2009; Larkin et al., 2009; Huang and Zheng, 2010). However, in the rats that were exercised to physical exhaustion, the lipid profiles did not vary significantly, probably because of the great perturbations in homeostasis caused by the excessive exercise. For the remaining parameters such as hepatic function (AST and ALT) and nutritional state (total serum protein), the changes observed were within the normal range, attesting to the regular health state of animals on both diets. The glucose levels were significantly lower in the rats fed common cheese and submitted to intense exercise, which could be related to the fact that physical exhaustion may result in the depletion of energetic substrates and a decrease in glucose levels (Lima-Silva et al., 2009).

\section{Limitations of the Study}

The present study presents limitations. Only a limited number of immunological parameters (14 in total) were analyzed. Therefore, further studies exploring additional immunological parameters such as cytokines and hormone responses to probiotic cheese and exhaustive exercise could improve our knowledge on this topic. In addition, analysis of free radicals was not performed, even though it has been reported that exercise increases the amount of free radicals, which could influence the immune system (Knight, 2000). However, our study highlights some important and interesting findings, creating new avenues for the use of probiotic dairy foods in athletes and physically active individuals. Further studies should explore the probiotic supplementation of other food matrices such as whey beverages and dairy desserts.

\section{CONCLUSIONS}

One single session of exhaustive exercise in sedentary rats was sufficient to induce immune suppression,

Table 5. Biochemical parameters ${ }^{1}$

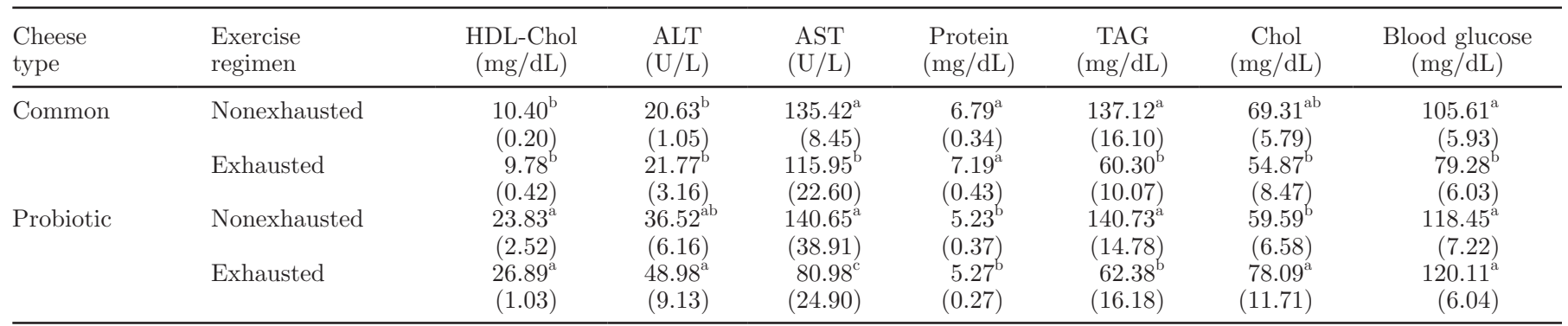

\footnotetext{
${ }^{\mathrm{a}-\mathrm{c}}$ Means within each column with different letters indicate significant differences at the $5 \%$ level.

${ }^{1}$ After being fed either the conventional (common) or the probiotic cheese for $2 \mathrm{wk}$, half of the animals from each group were exercised to exhaustion on the treadmill and blood samples were analyzed $2 \mathrm{~h}$ later. The other rats (nonexhausted) were removed from their cages and sacrificed for comparison. Data are means (SEM in parentheses) of high-density lipoprotein (HDL), alanine transaminase (ALT), aspartate transaminase (AST), protein (total serum proteins), triacylglycerols (TAG), and total cholesterol (Chol).
} 
which could increase the chances of opportunistic infections. The consumption of a probiotic cheese containing L. acidophilus LA 14 and B. longum BL 05 for $14 \mathrm{~d}$ prior to the exercise session showed a possible attenuating effect on the immune suppression induced by exhausting exercise. Many sources of stress can mirror the hormonal pattern and immune suppression caused by exercise (e.g., surgery, trauma, burns, sepsis; Pedersen and Hoffman-Goetz, 2000), and individuals in these situations could use probiotics to strengthen their immune systems. Without affecting the proportion of macronutrients, improvements in the lipid pattern were obtained by consuming the probiotic cheese. The remaining parameters indicated that the treatment was safe and that the animals maintained a normal state of health throughout the study. Probiotic cheese may be a viable alternative to maximize health and, indirectly, the physical performance of athletes. Further research will be needed to establish the minimum treatment time and probiotic dosages necessary to guarantee the same health benefits brought about by consuming this type of food.

\section{ACKNOWLEDGMENTS}

The authors thank both CNPq (Brazilian National Council for Research) and FAPESP (the State of São Paulo Research Foundation; grant 2009/00059-0) for their fellowships and financial support.

\section{REFERENCES}

Abcouwer, S. F. 2000. Effects of glutamine on immune cells. Nutrition 16:67-69

Agencia Estado. 2009. Cresce número de brasileiros que praticam atividade física. Accessed Jan. 30, 2012. http://www.abril.com.br/noticias/ciencia-saude/cresce-numero-brasileiros-praticam-atividadefisica-433158.shtml.

Albenzio, M., A. Santillo, M. Caroprese, R. Marino, A. Trani, and M. Faccia. 2010. Biochemical patterns in ovine cheese: Influence of probiotic strains. J. Dairy Sci. 93:3487-3496.

AOAC. 2002. Official Methods of Analysis. 17th ed. Association of Official Analytical Chemists International, Gaithersburg, MD.

Asemi, Z., M. Samimi, Z. Tabasi, P. Talebian, Z. Azarbad, Z. Hydarzadeh, and A. Esmaillzadeh. 2011. Effect of daily consumption of probiotic yoghurt on lipid profiles in pregnant women: A randomized controlled clinical trial. J. Matern. Fetal Neonat. http:// dx.doi.org/10.3109/14767058.2011.640372.

Ataie-Jafari, A., B. Larijani, H. AlaviMajd, and F. Tahbaz. 2009 Cholesterol-lowering effect of probiotic yogurt in comparison with ordinary yogurt in mildly to moderately hypercholesterolemic subjects. Ann. Nutr. Metab. 54:22-27.

Berg, A., H. M. Muller, S. Rathmann, and P. Deibert. 1999. The gastrointestinal system an essential target organ of the athlete's health and physical performance. Exerc. Immunol. Rev. 5:78-95.

Bergamini, C. V., E. R. Hynes, A. Quiberoni, V. B. Suárez, and C. A. Zalazar. 2005. Probiotic bacteria as adjunct starters: Influence of the addition methodology on their survival in a semi-hard Argentinean cheese. Food Res. Int. 38:597-604.

Blannin, A. K., L. J. Chatwin, R. Cave, and M. Gleeson. 1996. Effects of submaximal cycling and long-term endurance training on neutrophil phagocytic activity in middle-aged men. Br. J. Sports Med. 30:125-129.

Bloomer, R. J. 2008. Effect of exercise on oxidative stress biomarkers. Adv. Clin. Chem. 46:1-50.

Borchers, A. T., C. Selmi, F. J. Meyers, C. L. Keen, and M. E. Gershwin. 2009. Probiotics and immunity. J. Gastroenterol. 44:26-46.

Brenner, I., P. N. Shek, J. Zamecnik, and R. J. Shephard. 1998. Stress hormones and the immunological responses to heat and exercise. Int. J. Sports Med. 19:130-143.

Buriti, F. C. A., J. S. Rocha, E. G. Assis, and S. M. I. Saad. 2005a Probiotic potential of Minas fresh cheese prepared with the addition of Lactobacillus paracasei. Lebenson. Wiss. Technol. 38:173180.

Buriti, F. C. A., J. S. Rocha, and S. M. I. Saad. 2005b. Incorporation of Lactobacillus acidophilus in Minas fresh cheese and its implications for textural and sensorial properties during storage. Int. Dairy J. 15:1279-1288.

Cruz, A. G., F. C. A. Buriti, C. B. H. Souza, J. A. F. Faria, and S. M. I. Saad. 2009. Probiotic cheese: Health benefits, technological and stability aspects. Trends Food Sci. Technol. 20:344-354.

Cruz, A. G., R. S. Cadena, J. A. F. Faria, H. M. A. Bolini, C. Dantas, M. M. C. Ferreira, and R. Deliza. 2012a. PARAFAC: Adjustment for modeling consumer study covering probiotic and conventional yogurt. Food Res. Int. 45:211-215.

Cruz, A. G., R. S. Cadena, J. A. F. Faria, C. A. F. Oliveira, R. N. Cavalcanti, E. Bona, H. M. A. Bolini, and M. A. A. P. Da Silva. 2011. Consumer acceptability and purchase intent of probiotic yoghurt with added glucose oxidase using sensometrics, artificial neural networks and logistic regression. Int. J. Dairy Technol. 64:549-556.

Cruz, A. G., W. F. Castro, J. A. F. Faria, S. Bogusz Jr., S. D. Granato, R. M. S. Celeguini, J. Lima-Pallone, and H. T. Godoy. 2012b. Glucose oxidase: A potential option to decrease the oxidative stress in stirred probiotic yogurt. Lebenson. Wiss. Technol. 47:512-515.

Cruz, A. G., W. F. Castro, J. A. F. Faria, P. C. B. Lollo, J. AmayaFarfán, M. Q. Freitas, D. Rodrigues, C. A. F. Oliveira, and H. T. Godoy. 2012c. Probiotic yogurts manufactured with increased glucose oxidase levels: Postacidification, proteolytic patterns, survival of probiotic microorganisms, production of organic acid and aroma compounds. J. Dairy Sci. 95:2261-2269.

Cruz, A. G., J. A. F. Faria, E. H. M. Walter, R. R. Andrade, R. N. Cavalcanti, C. A. F. Oliveira, and D. Granato. 2010. Processing optimization of probiotic yogurt containing glucose oxidase using response surface methodology. J. Dairy Sci. 93:5059-5068.

De Almeida, M. H. B., S. S. Zoellner, A. G. Cruz, M. R. L. Moura, L. M. J. De Carvalho, M. C. J. Freitas, and A. D. S. Sant'Ana. 2008. Potentially probiotic açaí yogurt. Int. J. Dairy Technol. $61: 178-182$.

de Vrese, M., P. Winkler, P. Rautenberg, T. Harder, C. Noah, C. Laue, S. Ott, J. Hampe, S. Schreiber, K. Heller, and J. Schrezenmeir. 2006. Probiotic bacteria reduced duration and severity but not the incidence of common cold episodes in a double blind, randomized, controlled trial. Vaccine 24:6670-6674.

de Vrese, M., and J. Schrezenmeir. 2008. Probiotics, prebiotics, and synbiotics. Adv. Biochem. Eng. Biotechnol. 111:1-66.

Ejtahed, H. S., J. Mothtadi-Nia, A. Homayouni-Rad, M. Niafar, M Asghari-Jafarabadi, V. Mofid, and A. Akbarian-Moghari. 2011. Effect of probiotic yogurt containing Lactobacillus acidophilus and Bifidobacterium lactis on lipid profile in individuals with type 2 diabetes mellitus. J. Dairy Sci. 94:3288-3294.

Espírito Santo, A. P. D., R. C. Silva, F. A. S. M. Soares, D. Anjos, L. A. Gioielli, and M. N. Oliveira. 2010. Açai pulp addition improves fatty acid profile and probiotic viability in yoghurt. Int. Dairy J. $20: 415-422$.

Fabian, E., and I. Elmadfa. 2006. Influence of daily consumption of probiotic and conventional yoghurt on the plasma lipid profile in young healthy women. Ann. Nutr. Metab. 50:387-393.

Fritzen-Freire, C. B., C. M. O. Muller, J. B. Laurindo, R. M. C. Amboni, and E. S. Prudêncio. 2010a. The effect of direct acidification on the microbiological physicochemical and sensory properties of probiotic Minas Frescal cheese. Int. J. Dairy Technol. 63:561-568. 
Fritzen-Freire, C. B., C. M. O. Muller, J. B. Laurindo, and E. S. Prudêncio. 2010b. The influence of Bifidobacterium Bb-12 and lactic acid incorporation on the properties of Minas Frescal cheese. J. Food Eng. 96:621-627.

Gill, H. S., and M. L. Cross. 2002. Probiotics and immune function. Pages 251-272 in Nutrition and Immune Function. P. C. Calder, C. J. Field, and H. S. Gill, ed. CABI, Oxford, UK.

Gill, R., A. Tsung, and T. Billiar. 2010. Linking oxidative stress to inflammation: Toll-like receptors. Free Radic. Biol. Med. 48:11211132 .

Gleeson, M. 2000. Mucosal immunity and respiratory illness in elite athletes. Int. J. Sports Med. 21(Suppl. 1):S33-S43.

Gleeson, M. 2007. Immune function in sport and exercise. J. Appl. Physiol. 103:693-699.

Gomes, A. A., S. P. Braga, A. G. Cruz, R. S. Cadena, J. A. F. Faria, P. C. Lollo, J. Amaya-Farfan, C. C. Carvalho, and H. M. A. Bolini. 2011a. Effect of the inoculation level of L. acidophilus in probiotic cheese on the physicochemical features and sensory performance towards commercial cheeses. J. Dairy Sci. 94:4777-4786.

Gomes, A. P., A. G. Cruz, R. S. Cadena, R. M. S. Granato, D. Celeghini, J. A. F. Faria, H. M. A. Bolini, and M. A. R. Pollonio. 2011b. Low sodium Minas fresh cheese manufacture: Effect of the partial replacement of $\mathrm{NaCl}$ with $\mathrm{KCl}$. J. Dairy Sci. 94:2701-2706.

Granato, D., G. F. Branco, A. G. Cruz, J. A. F. Faria, and N. P. Shah. 2010. Probiotic dairy products as functional foods. Comp. Rev. Food Sci. Food Saf. 9:455-470.

Guarino, A., A. Lo Vecchio, and R. B. Canani. 2009. Probiotics as prevention and treatment for diarrhea. Curr. Opin. Gastroenterol. $25: 18-23$.

Hamer, M., D. Wolvers, and R. Albers. 2004. Using stress models to evaluate immuno-modulating effects of nutritional intervention in healthy individuals. J. Am. Coll. Nutr. 23:637-646.

Hatakka, K., A. J. Ahola, H. Yli-Knuuttila, M. Richardson, T. Poussa, J. H. Meurman, and R. Korpela. 2007. Probiotics reduce the prevalence of oral Candida in the elderly a randomized controlled trial. J. Dent. Res. 86:125-130.

Hoffman-Goetz, L., and B. K. Pedersen. 1994. Exercise and the immune system: A model of the stress response? Immunol. Today $15: 382-387$.

Huang, Y., and Y. Zheng. 2010. The probiotic Lactobacillus acidophilus reduces cholesterol absorption through the down-regulation of Niemann-Pick C1-like 1 in Caco-2 cells. Br. J. Nutr. 103:473-478.

Ibrahim, F., S. Ruvio, L. Granlund, S. Salminen, M. Viitanen, and A. C. Ouwehand. 2010. Probiotics and immunosenescence: Cheese as a carrier. FEMS Immunol. Med. Microbiol. 59:53-59.

Im, S. S., L. Yousef, C. Blaschitz, J. Z. Liu, R. A. Edwards, S. G. Young, M. Raffatellu, and T. F. Osborne. 2011. Linking lipid metabolism to the innate immune response in macrophages through sterol regulatory element binding protein-1a. Cell Metab. 13:540549 .

Inouye, M., K. Silander, E. Hamalainen, V. Salomaa, K. Harald, P. Jousilahti, S. Mannisto, J. G. Eriksson, J. Saarela, S. Ripatti, M. Perola, G. J. van Ommen, M. R. Taskinen, A. Palotie, E. T. Dermitzakis, and L. Peltonen. 2010. An immune response network associated with blood lipid levels. PLoS Genet. 6:e1001113.

Karimi, R., A. M. Mortazavian, and A. G. Cruz. 2011. Viability of probiotic microorganisms in cheese during production and storage: A review. J. Dairy Sci. Technol. 91:283-308.

Keil, D., R. W. Luebke, and S. B. Pruett. 2001. Quantifying the relationship between multiple immunological parameters and host resistance: Probing the limits of reductionism. J. Immunol. $167: 4543-4552$.

Knight, J. A. 2000. Review: Free radicals, antioxidants, and the immune system. Ann. Clin. Lab. Sci. 30:145-158.

Lahtinen, S. J., S. Forssten, J. Aakko, L. Granlund, N. Rautonen, S. Salminen, M. Viitanen, and A. C. Ouwehand. 2012. Probiotic cheese containing Lactobacillus rhamnosus HN001 and Lactobacillus acidophilus $\mathrm{NCFM}\left({ }^{\circledR}\right)$ modifies subpopulations of fecal lactobacilli and Clostridium difficile in the elderly. Age (Dordr.) $34: 133-143$.
Larkin, T. A., L. B. Astheimer, and W. E. Price. 2009. Dietary combination of soy with a probiotic or prebiotic food significantly reduces total and LDL cholesterol in mildly hypercholesterolaemic subjects. Eur. J. Clin. Nutr. 63:238-245.

Lima-Silva, A. E., F. R. De-Oliveira, F. Y. Nakamura, and M. S. Gevaerd. 2009. Effect of carbohydrate availability on time to exhaustion in exercise performed at two different intensities. Braz. J. Med. Biol. Res. 42:404-412.

Mackinnon, L. T. 2000. Chronic exercise training effects on immune function. Med. Sci. Sports Exerc. 32:S369-376.

Madureira, A. R., T. Brandão, A. M. Pintado, M. E. Gomes, and F. X. Malcata. 2011a. Technological optimization of manufacture of probiotic whey cheese matrices. J. Food Sci. 76:E203-E211.

Madureira, A. R., A. I. Pintado, A. M. Gomes, M. E. Pintado, and F. X. Malcata. 2011b. Protective effect of whey cheese matrix on probiotic strains exposed to simulated gastrointestinal conditions. Lebenson. Wiss. Technol. 44:75-81.

Madureira, A. R.. A. I. Pintado, A. M. Gomes, M. E. Pintado, and F. X. Malcata. 2011c. Rheological, textural and microstructural features of probiotic whey cheeses. Lebenson. Wiss. Technol. $44: 75-81$

Martarelli, D., M. C. Verdenelli, S. Scuri, M. Cocchioni, S. Silvi, C. Cecchini, and P. Pompei. 2011. Effect of a probiotic intake on oxidant and antioxidant parameters in plasma of athletes during intense exercise training. Curr. Microbiol. 62:1689-1696.

McCarthy, D. A., and M. M. Dale. 1988. The leucocytosis of exercise. A review and model. Sports Med. 6:333-363.

Medici, M., C. G. Vinderola, and G. Perdigón. 2004. Gut mucosal immunomodulation by probiotic fresh cheese. Int. Dairy J. 14:611618

Minervini, F., S. Siragusa, M. Faccia, F. Dal Bello, M. Gobbetti, and M. De Angelis. 2012. Manufacture of Fior di Latte cheese by incorporation of probiotic lactobacilli. J. Dairy Sci. 95:508-520.

Minocha, A. 2009. Probiotics for preventive health. Nutr. Clin. Pract. $24: 227-241$.

Modzelewska-Kapituła, M., J. A. N. Kobukowski, and L. Kłebukowska. 2010. The influence of feeding diets containing white cheese, produced with prebiotics and the potentially probiotic Lactobacillus plantarum strain, on the gastrointestinal microflora of rats. Czech J. Food Sci. 28:139-145.

Nichols, A. W. 2007. Probiotics and athletic performance: A systematic review. Curr. Sports Med. Rep. 6:269-273.

Ogué-Bon, E., C. Khoo, L. Hoyles, A. L. McCartney, G. R. Gibson, and R. A. Rastall. 2011. In vitro fermentation of rice bran combined with Lactobacillus acidophilus 14 or Bifidobacterium longum 05 by the canine faecal microbiota. FEMS Microbiol. Ecol. $75: 365-376$

Pedersen, B. K., and L. Hoffman-Goetz. 2000. Exercise and the immune system: Regulation, integration, and adaptation. Physiol. Rev. 80:1055-1081.

Pflanzer Junior, S. B., A. G. Cruz, A. S. Sant'ana, M. R. L. Moura, L. M. J. Carvalho, and R. Silva. 2009. Food safety knowledge of cheese consumers. J. Food Sci. 94:28-30.

Pregliasco, F., G. Anselmi, L. Fonte, F. Giussani, S. Schieppati, and L. Soletti. 2008. A new chance of preventing winter diseases by the administration of synbiotic formulations. J. Clin. Gastroenterol. 42(Suppl. 3 Pt. 2):S224-S233.

Pyne, D. B., and M. Gleeson. 1998. Effects of intensive exercise training on immunity in athletes. Int. J. Sports. Med. 19(Suppl. 3):S183-S191; discussion S191-184.

Pyne, D. B., W. A. McDonald, M. Gleeson, A. Flanagan, R. L. Clancy, and P. A. Fricker. 2001. Mucosal immunity, respiratory illness, and competitive performance in elite swimmers. Med. Sci. Sports Exerc. 33:348-353

Ross, R. P., G. Fitzgerald, K. Collins, and C. Stanton. 2002. Cheese delivering biocultures: Probiotic cheese. Aust. J. Dairy Technol. $57: 71-78$.

Rowbottom, D. G., and K. J. Green. 2000. Acute exercise effects on the immune system. Med. Sci. Sports Exerc. 32(Suppl.):S396S405. 
Saad, S. M. I., A. G. Cruz, and J. A. F. Faria. 2011. Probióticos e Prebióticos em Alimentos: Fundamentos e Aplicações Tecnológicas. Varela, São Paulo, Brazil.

Savard, P., B. Lamarche, M.-E. Paradis, H. Thiboutot, E. Laurin, and D. Roy. 2011. Impact of Bifidobacterium animalis ssp. lactis BB 12 and Lactobacillus acidophilus LA 5-containing yoghurt, on fecal bacterial counts of healthy adults. Int. J. Food Microbiol. 149:50-57.

Saxelin, M., R. Korpela, and A. Mayra-Makinen. 2003. Introduction Classifying functional dairy products. Pages 1-16 in Functional Dairy Products. T. Mattila-Sandholm and M. Saarela, ed. CRC Press, Boca Raton, FL.

Senchina, D. S. 2009. Effects of regular exercise on the aging immune system: A review. Clin. J. Sport Med. 19:439-440.

Souza, C. H. B., and S. M. I. Saad. 2009. Viability of Lactobacillus acidophilus La-5 added solely or in co-culture with a yoghurt starter culture and implications on physico-chemical and related properties of Minas fresh cheese during storage. Lebenson. Wiss. Technol. 42:633-640.

Souza, T. B., A. G. Cruz, M. R. L. Moura, A. C. M. Vieira, and A. S. Sant'Ana. 2008. Microscopic quality indicators of Minas frescal cheese. Food Contr. 19:71-75.

Steel, J. M., C. M. Steel, and F. D. Johnstone. 1987. Leukocytosis induced by exercise. Br. Med. J. (Clin. Res. Ed.) 295:1135-1136.

Steensberg, A. 2003. The role of IL-6 in exercise-induced immune changes and metabolism. Exerc. Immunol. Rev. 9:40-47.
Steensberg, A., G. van Hall, T. Osada, M. Sacchetti, B. Saltin, and B. Klarlund Pedersen. 2000. Production of interleukin-6 in contracting human skeletal muscles can account for the exercise-induced increase in plasma interleukin-6. J. Physiol. 529:237-242.

Todorov, S. D., D. N. Furtado, S. M. I. Saad, and B. D. G. M. Franco. 2011. Bacteriocin production and resistance to drugs are advantageous features for Lactobacillus acidophilus La-14, a potential probiotic strain. New Microbiol. 34:357-370.

West, N. P., D. B. Pyne, A. W. Cripps, W. G. Hopkins, D. C. Eskesen, A. Jairath, C. T. Christophersen, M. A. Conlon, and P. A. Fricker 2011. Lactobacillus fermentum (PCC ${ }^{\circledR}$ ) supplementation and gastrointestinal and respiratory-tract illness symptoms: A randomised control trial in athletes. Nutr. J. 10:30.

West, N. P., D. B. Pyne, J. M. Peake, and A. W. Cripps. 2009. Probiotics, immunity and exercise: A review. Exerc. Immunol. Rev. 15:107-126.

White, J. A., R. J. Hart, and J. C. Fry. 1986. An evaluation of the Waters Pico-Tag system for the amino acid analysis of food materials. J. Automat. Chem. 8:170-177.

Woods, J. A., V. J. Vieira, and K. T. Keylock. 2009. Exercise, inflammation, and innate immunity. Immunol. Allergy Clin. North Am. $29: 381-393$

Zahorec, R. 2001. Ratio of neutrophil to lymphocyte counts-Rapid and simple parameter of systemic inflammation and stress in critically ill. Bratisl. Lek Listy (Tlacene Vyd) 102:5-14. 